\title{
Reaction of Lithium (2,3-Dimethyl-2-butyl)-t-butoxyborohydride with Selected Organic Compounds Containing Representative Functional Groups
}

\author{
Jin Soon Cha ${ }^{*}$ and Dae Yon Lee \\ Department of Chemistry, Institute of Natural Sciences and Institute of New Material Chemistry. \\ Yeungnam Unversity, Gyongsan 712-749, Korea \\ Received April 1, 2002
}

\begin{abstract}
The general reducing characteristics of a newly synthesized reducing agent, lithium (2,3-dimethyl-2-butyl)-tbutoxyborohydride ( $\mathrm{Li} \mathrm{Thx}^{\prime} \mathrm{BuOBH}_{2}, 1$ ), in tetrahydrofuran (THF) toward selected organic compounds containing representative functional groups under practical conditions has been examined. The reagent revealed an interesting and unique reducing characteristics. Especially, the stereoselectivity in the reduction of cyclic ketones was extraordinary. Thus, the introduction of bulky alkyl and alkoxy groups into the parent borohydride affords a high stereoselectivity. In general, the reducing power of the reagent is somewhere between the diakylborohydride and the parent borohydride. This permits the reagent to be a reagent of choice for selective reduction of organic compounds with an improved selectivity.
\end{abstract}

Keywords : $\mathrm{Li}$ Thx'BuOBH${ }_{2}$, Reduction, Organic compounds.

\section{Introduction}

In contrast to the reducing characteristics of lithium borohydride ${ }^{1}$, its derivative lithium trialkylborohydride ${ }^{2-5}$ and dialkylborohydride ${ }^{6}$ are remarkably powerful and selective reducing agents. The introduction of alkyl groups accelerates the hydride donor activity tremendously. However, situation changes when alkoxy groups are introduced to lithium borohydride. For example, the reducing power of lithium triisopropoxyborohydride $^{7}$ is much milder than that of lithium borohydride ${ }^{1}$. Therefore, it appeared of interest to explore a mixed derivative, monoalkylmonoalkoxyborohydride, for its reducing characteristics.

Because of easy preparation of thexyl'butoxyborane (Thx'BuOBH) and its simple conversion into lithium thexylbutoxyborohydride ( $\mathrm{Li} \mathrm{Thx}^{\prime} \mathrm{BuOBH}_{2}, 1$ ), this derivative attracted our attention. Being a monoalkylmonoalkoxyborohydride, this reducing agent was anticipated to have different characteristics from those of dialkylborohydride such as lithium 9-boratabicyclo[3.3.1] nonane (Li 9-BBNH). ${ }^{6}$

We undertook a detailed study of the stoichiometry and products of the reaction of $\mathrm{Li} \mathrm{Thx}^{\prime} \mathrm{BuOBH}_{2}$ with selected organic compounds containing representative functional groups under the practical conditions.

\section{Results and Discussion}

Preparation of Lithium Thexyl'butoxyborohydride ( $\mathrm{Li}$ Thx $\left.{ }^{7} \mathbf{B u O B H}_{2}, 1\right)$ Solutions. Thexylborane (2,3-dimethyl-2butylborane) has been prepared by the hydroboration of 2,3dimethyl-2-butene with borane-THF in the ratio of $1: 1 .^{8}$ The reaction of thexylborane with excess tert-butyl alcohol at 0 and $25^{\circ} \mathrm{C}$ was examined and the results are summarized in Table 1. As shown in the table, although thexylborane possesses two B-H bonds, it reacts only 1 equiv of tert-butyl alcohol even in the presence of excess amount at 0 or $25^{\circ} \mathrm{C}$
(Eq. 1).

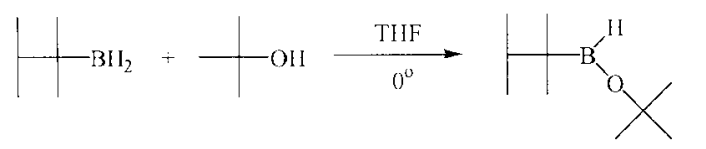

The ${ }^{11} \mathrm{~B}$ NMR spectrum of a solution of thexyl'butoxyborane in THF showed a doublet $\left(J_{\mathrm{B} \cdot \mathrm{H}}=390 \mathrm{~Hz}\right)$ centered at $\delta 48.3$ ppm relative to $\mathrm{BF}_{3} \cdot \mathrm{OEt}_{2}$.

A solution of lithium thexyl'butoxyborohydride ( $\mathrm{Li} \mathrm{Thx}{ }^{\mathrm{Bu}} \mathrm{B}-$

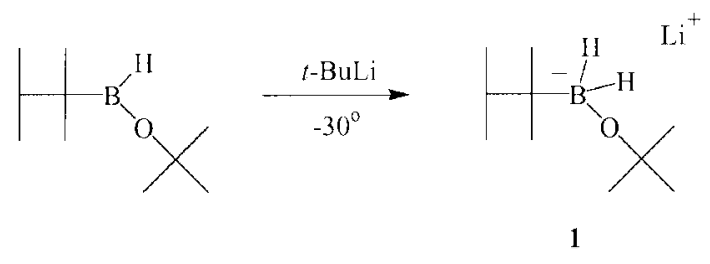

$\mathrm{OBH}_{2}$, 1) was prepared by adding a solution of tertbutyllithium ${ }^{9}$ in pentane to a solution of thexyl'butoxyborane in THF at $-30^{\circ} \mathrm{C}$ (Eq. 2). The ${ }^{11} \mathrm{~B}$ NMR of a solution of 1 in

Table 1. Reaction of Thexylborane with Excess itr-Butyl Alcohol in Tetrahydrofuran ${ }^{A}$

\begin{tabular}{ccc}
\hline Temperature ( $\left.{ }^{\circ} \mathrm{C}\right)$ & Time (min) & Hydrogen evolution $^{\text {h }}$ \\
\hline 0 & 1 & 0.56 \\
& 5 & 0.89 \\
& 15 & 0.91 \\
& 30 & 1.00 \\
25 & 6 & 1.01 \\
& 1 & 0.95 \\
& 5 & 1.00 \\
& 15 & 1.00 \\
& 30 & 1.00 \\
\hline
\end{tabular}

"Two equiv of alcohol reacted. "Mnol of per mmol of thexylborane. 
Table 2. Reaction of Lithium Thexyl'butoxyborohydride with Representative Active Hydrogen Compounds at $0^{\circ} \mathrm{C}^{10.6}$

\begin{tabular}{|c|c|c|c|c|}
\hline Compound & $\begin{array}{l}\text { Time } \\
\text { (h) }\end{array}$ & $\begin{array}{l}\text { Hydrogen } \\
\text { evolved }\end{array}$ & $\begin{array}{l}\text { Hydride } \\
\text { used }^{c}\end{array}$ & $\begin{array}{l}\text { Hydride used } \\
\text { for reduction }\end{array}$ \\
\hline \multirow[t]{3}{*}{ 1-hexanol } & 0.25 & 0.17 & 0.17 & 0.00 \\
\hline & 6 & 0.36 & 0.36 & 0.00 \\
\hline & 24 & 0.40 & 0.40 & 0.00 \\
\hline \multirow[t]{3}{*}{ benzyl alcohol } & 0.25 & 0.36 & 0.36 & 0.00 \\
\hline & 6 & 0.38 & 0.38 & 0.00 \\
\hline & 24 & 0.38 & 0.38 & 0.00 \\
\hline \multirow[t]{3}{*}{ 3-hexanol } & 0.25 & 0.12 & 0.12 & 0.00 \\
\hline & 6 & 0.38 & 0.38 & 0.00 \\
\hline & 24 & 0.39 & 0.39 & 0.00 \\
\hline \multirow[t]{3}{*}{ 3-ethyl-3-pentano } & 0.25 & 0.06 & 0.06 & 0.00 \\
\hline & 6 & 0.29 & 0.29 & 0.00 \\
\hline & 24 & 0.30 & 0.30 & 0.00 \\
\hline \multirow[t]{3}{*}{ phenol } & 0.25 & 0.98 & 0.98 & 0.00 \\
\hline & 1 & 1.01 & 1.01 & 0.00 \\
\hline & 6 & 1.01 & 1.01 & 0.00 \\
\hline \multirow{3}{*}{$n$-hexylamine ${ }^{d}$} & 0.25 & 0.02 & 0.02 & 0.00 \\
\hline & 6 & 0.17 & 0.17 & 0.00 \\
\hline & 24 & 0.18 & 0.18 & 0.00 \\
\hline \multirow[t]{3}{*}{ 1-hexanethiol } & 0.25 & 0.62 & 0.62 & 0.00 \\
\hline & 1 & 0.73 & 0.73 & 0.00 \\
\hline & 24 & 0.76 & 0.76 & 0.00 \\
\hline \multirow[t]{3}{*}{ benzenethiol } & 0.25 & 0.99 & 0.99 & 0.00 \\
\hline & 1 & 1.00 & 1.00 & 0.00 \\
\hline & 6 & 1.00 & 1.00 & 0.00 \\
\hline
\end{tabular}

In a nixed solvent of THF and pentane. "Reagent to compound is $1 ; 1$. "Mmol of hydride per $\mathrm{mmol}$ of compound. "Tw'o equiv of reagent utilized.

a mixed solvent of THF and pentane showed a triplet $\left(J_{\mathrm{B} \cdot \mathrm{H}}=\right.$ $219 \mathrm{~Hz}$ ) centered at $\delta-7.6 \mathrm{ppm}^{10}$ relative to $\mathrm{BF}_{3} \cdot \mathrm{OEt}_{2}$.

Alcohols, Phenols, Amines, and Thiols (Active Hydrogen
Table 3. Reaction of Lithium Thexylbutoxyborohydride with Representative Aldelyydes and Ketones at $0^{\circ} \mathrm{C}^{\circ}$

\begin{tabular}{lcclr}
\hline Compound & $\begin{array}{c}\text { Time } \\
(\mathrm{h})\end{array}$ & $\begin{array}{c}\text { Ratio of } \\
\text { rgt/cmpd }\end{array}$ & Product & $\begin{array}{r}\text { Yield } \\
(\%)^{5}\end{array}$ \\
\hline caproaldehyde & 0.5 & 0.5 & l-hexanol & 99 \\
benzaldehyde & 0.5 & 0.5 & benzyl alcohol & 99.5 \\
& 1.0 & 0.5 & benzyl alcohol & 99.0 \\
2-heptanone & 0.5 & 0.5 & 2-heptanol & 98.5 \\
norcamphor & 0.5 & 0.5 & norborneol & 99 \\
acetophenone & 3 & 0.5 & l-phenylethanol & 81 \\
& 0.5 & 1.0 & l-phenylethanol & 100 \\
benzophenone & 3 & 0.5 & benzhydrol & 38 \\
& 0.5 & 1.0 & benzhydrol & 78 \\
& 0.5 & 2.0 & benzhydrol & 100 \\
cinnamaldehyde & 0.5 & 0.5 & cinnamyl alcohol & 99.5 \\
\hline
\end{tabular}

"See the corresponding footnote in Table 2. Analyzed by GC with a suitable internal standard.

Compounds). Among the alcohols examined, only phenol liberated hydrogen relatively fast and quantitatively. All the primary, secondary and tertiary alcohols examined liberated hydrogen very showly and finally the hydrogen evolution was incomplete within 24 hours under the experimental conditions. The primary amine, $n$-hexylamine, also liberated hydrogen very slowly. The thiols examined appeared to be relatively reactive toward the reagent. Thus, 1-hexanethiol evolved about $70 \%$ hydrogen in $1 \mathrm{~h}$ and benzenethiol liberated a quantitative hydrogen within $1 \mathrm{ll}$. The results are summarized in Table 2 .

Aldehydes and Ketones. Simple aldehydes and ketones listed in Table 3 were cleanly reduced to the corresponding alcohols with the stoichiometric amount (a half equivalent) of $\mathbf{1}$. However, the reaction of aromatic ketones, such as acetophenone and benzophenone, with the stoichiometric

Table 4. Stereoselectivity in the Reduction of Cyclic Ketones with Lithium Thexyl'butoxyborohydride ${ }^{a . b}$

\begin{tabular}{|c|c|c|c|c|c|}
\hline Ketone & $\begin{array}{c}\text { Temperature } \\
\left({ }^{\circ} \mathrm{C}\right)\end{array}$ & $\begin{array}{l}\text { Time } \\
\text { (h) }\end{array}$ & $\begin{array}{l}\text { Conversion } \\
\text { yield }(\%)^{6}\end{array}$ & $\begin{array}{l}\text { Less stable } \\
\text { isomer }\end{array}$ & $\begin{array}{c}\text { Selectivity } \\
(\%)\end{array}$ \\
\hline \multirow[t]{2}{*}{ 2-methylcyclopentanone } & 0 & 0.5 & 100 & cis & $>99.5$ \\
\hline & -20 & 0.5 & 100 & & $>99.5$ \\
\hline \multirow{2}{*}{ 2-methylcyclohexanone } & 0 & 0.5 & 100 & cis & $>99.5$ \\
\hline & -20 & 0.5 & 100 & & $>99.9$ \\
\hline \multirow[t]{2}{*}{ 2-t-butylcyclohexanone } & 0 & 6 & 100 & cis & $>99.5$ \\
\hline & -20 & 12 & 100 & & $>99.9$ \\
\hline \multirow[t]{2}{*}{ 3-methylcyclohexanone } & 0 & 0.5 & 100 & trans & 96 \\
\hline & -20 & 0.5 & 100 & & 98 \\
\hline \multirow[t]{2}{*}{ 4-methylcyclohexanone } & 0 & 0.5 & 100 & cis & 92 \\
\hline & -20 & 0.5 & 100 & & 94 \\
\hline \multirow{2}{*}{ 4-t-butylcyclohexanone } & 0 & 0.5 & 100 & cis & 95 \\
\hline & -20 & 0.5 & 100 & & 97 \\
\hline \multirow[t]{2}{*}{ 3,3,5-trimethylcyclohexanone } & 0 & 0.5 & 100 & trans & $>99.5$ \\
\hline & -20 & 0.5 & 100 & & $>99.9$ \\
\hline \multirow[t]{2}{*}{ norcamphor } & 0 & 0.5 & 100 & endo & 98 \\
\hline & -20 & 0.5 & 100 & & 99.5 \\
\hline \multirow[t]{2}{*}{ camphor } & 0 & 48 & 56 & exo & $>99.5$ \\
\hline & -20 & 72 & 100 & & $>99.5$ \\
\hline
\end{tabular}

See the corresponding footnote in Table $2 .{ }^{b} \mathrm{~A} 2: 1$ ratio for reagent to compound was utilized. "Analyzed by GC. 
Table 5. Comparison of Stereoselectivity in the Reduction of Cyclic Ketones with Representative Reagents at $0^{\circ} \mathrm{C}$

\begin{tabular}{|c|c|c|c|c|c|}
\hline \multirow{2}{*}{ Ketone } & \multicolumn{5}{|c|}{ Selectivity $(\%)^{\prime \prime}$} \\
\hline & $\mathrm{Li}$ Thx'BuOBH & K 9-OThx-9-BBNH ${ }^{h}$ & $\mathrm{Lij}^{s} \mathrm{Bu}_{3} \mathrm{BH}^{c}$ & $\mathrm{Li} \mathrm{Sia}_{j} \mathrm{BH}^{\hat{h}}$ & $\mathrm{~K} 9-^{\prime} \mathrm{Bu}-9-\mathrm{BBNH}^{d}$ \\
\hline 2-methylcyclohexanone & $>99.5$ & 98.5 & 99.3 & 99.4 & 99.5 \\
\hline 3-methylcyclohexanone & 96 & 90 & 85 & 98 & 96 \\
\hline 4-methylcyclohexanone & 92 & 85.5 & 80.5 & 93 & 94 \\
\hline 4-t-butylcyclohexanone & 95 & 87 & 87.5 & 96.5 & 98.5 \\
\hline 3,3,5-trimethylcyclohexanone & $>99.5$ & $>99.9$ & 99.8 & 99 & 99 \\
\hline norcamphor & 98 & 95 & 99.6 & 99 & 95.5 \\
\hline camphor & $>99.5$ & 97.5 & 99.6 & $>99.9$ & 99.9 \\
\hline
\end{tabular}

"Analyzed by GC. The figures are ratio of the themodynamically less stable epimers. 'Data taken from ref. 11. "Data taken from ref. 13. "Data taken from ref. 12 .

amount was relatively slow, requiring a higher concentration of the reagent. In practice, one or two equivalents of reagent was needed to reduce such ketones completely to the corresponding alcohols. In the case of cinnamaldehyde, the reagent in a stoichiometric amount reduced it cleanly in a fashion of 1,2 -reduction to provide cinnamyl alcohol in a yield of $99.5 \%$

Stereoselectivity Study. The stereoselectivity of the reagent 1 in the reduction of cyclic ketones is summarized in Table 4 and the compared data achieved by other representative reagents are listed in Table 5.

The reagent revealed an excellent stereoselectivity in the reduction of representative cyclic ketones both at 0 or -20 ${ }^{\circ} \mathrm{C}$. Its stereoselectivity is comparable to the results previously achieved with lithium trisiamylborohydride $\left(\mathrm{Li} \mathrm{Sia} \mathrm{B}_{3} \mathrm{BH}\right)^{11}$ and potassium 9-butyl-9-boratabicyclo[3.3.1]nonane (K 9-Bu-9-BBNH), ${ }^{1 ?}$ even higher than the selectivity shown by lithium tri'butylborohydride ( $\mathrm{Li}^{3} \mathrm{Bu}_{3} \mathrm{BH}$ ) ${ }^{13}$ and potassium 9(2,3-dimethyl-2-butoxy)-9-boratabicyclo[3.3.1]nonane ( $\mathrm{K}$ 9-OThx-9-BBNH) ${ }^{1]}$ at $0^{\circ} \mathrm{C}$.

Quinones. Two examples for quinones were examined with 2 equiv of the reagent $\left(\mathrm{H}^{-} / \mathrm{compd}=4\right)$ at $0^{\circ} \mathrm{C}$. The reaction of $p$-benzoquinone produced hydroquinone and 1,4-dihydroxycyclohexadiene in a $50: 50$ distribution ratio, along with 0.5 equiv of hydrogen evolution, whereas anthraquinone was reduced completely to give a quantitative yield of 9,10 dihydro-9,10-anthracenediol. The experimental data are summarized in Table 6 .

Carboxylic Acids and Derivatives. Carboxylic acids and their derivatives were examined with an excess amount of

Table 6. Reaction of Lithium Thexyl'butoxyborohydride with Representative Quinones at $0^{\circ} \mathrm{C}^{a . b}$

\begin{tabular}{lclc}
\hline Compound & $\begin{array}{c}\text { Time } \\
\text { (h) }\end{array}$ & Product & $\begin{array}{c}\text { Yield } \\
(\%)^{c}\end{array}$ \\
\hline p-benzoquinonet & 12 & $\begin{array}{l}\text { hydroquinone } \\
\text { 1.4-dihydroxycyclohexadiene }\end{array}$ & 48 \\
Anthraquinone & 12 & $\begin{array}{l}9,10 \text {-dihydroxyanthracene } \\
\text { 9.10-dihydro-9.10- }\end{array}$ & 0 \\
& & 99.9 \\
& & dihydroxyanthracenediol & \\
\hline
\end{tabular}

See the corresponding footnote in Table 2. 'Two equiv of reagent utilized. "Analyzed by GC. "Along with 0.5 equiv of hydrogen evolution 'No hydrogen evolved.
Table 7. Reaction of Lithium Thexyl'butoxyborohydride with Representative Carboxylic Acids and Their Derivatives at $0^{\circ} \mathrm{C}^{a}$

\begin{tabular}{lllll}
\hline Compound & $\begin{array}{c}\text { Time } \\
(\mathrm{h})\end{array}$ & $\begin{array}{c}\text { Ratio of } \\
\text { rgt/cmpd }\end{array}$ & Product & $\begin{array}{c}\text { Yield } \\
(\%)^{b}\end{array}$ \\
\hline caproic acid & 60 & 2.0 & none & \\
& $24^{d}$ & 2.0 & none & \\
benzoic acid & 60 & 2.0 & none & \\
& $24^{d}$ & 2.0 & none & \\
caproyl chloride & 3 & 1.5 & l-hexanol & 98 \\
benzoyl chloride & 3 & 1.5 & benzyl alcohol & 99 \\
ethyl caproate & 3 & 2.0 & l-hexanol & 98 \\
ethyl benzoate & 3 & 2.0 & benzyl alcohol & 98 \\
capronitrile & 3 & 2.0 & l-hexanol & 98 \\
benzonitrile & 3 & 2.0 & benzyl alcohol & 97 \\
caproamide & 60 & 2.0 & none & \\
& $24^{d}$ & 2.0 & none & \\
benzamide & 60 & 2.0 & none & \\
& $24^{d}$ & 2.0 & none & \\
$N, N$-dimethylcaproamide & 60 & 2.0 & none & \\
$N, N$-dimethylbenzamide & $24^{d}$ & 2.0 & none & \\
& $24^{d}$ & 2.0 & none & none \\
\hline
\end{tabular}

"See the corresponding footnote in Table 2. "Analyzed by GC. Inmediately 1 equiv of lydrogen evolved. ${ }^{A} \mathrm{At} 25^{\circ} \mathrm{C}$. "No lydrogen evolved.

the reagent at $0{ }^{\circ} \mathrm{C}$. The acids reacted with the reagent to evolve a quantitative amount of hydrogen immediately but the further reduction was not followed at all, whereas the primary and tertiary amides were inert to this reagent without any evolution of hydrogen. However, the acid chlorides, esters and nitriles were reduced readily and cleanly to the corresponding alcohols. The results are summarized in Table 7.

Sulfur Compounds. Among the sulfur compounds listed in Table 8, only the aliphatic disulfide, di-n-butyl disulfide, underwent quantitative reduction to $n$-butanethiol, along with 1 equiv of hydrogen evolution. Other sulfur compounds, such as aromatic disulfides, sulfoxides and sulfones, were inert to this reagent. Although methanesulfonic acid evolved 1 equiv of hydrogen immediately, no reduction was followed.

Epoxides. The results of reducing three epoxides are 
Table 8. Reaction of Lithium Thexyltbutoxyborohydride with Representative Sulfur Compounds at $0^{\circ} \mathrm{C}^{a}$

\begin{tabular}{lrcll}
\hline Compound & $\begin{array}{c}\text { Time } \\
\text { (h) }\end{array}$ & $\begin{array}{c}\text { Ratio of } \\
\text { Igt/cmpd }\end{array}$ & Product & $\begin{array}{c}\text { Yield } \\
(\%)^{2}\end{array}$ \\
\hline di-fn-butyl disulfide & 6 & 1.5 & n-butanethiol & 99 \\
diphenyl disulfide & 24 & 1.5 & none & \\
dimethyl sulfoxide & 24 & 1.5 & none & \\
diphenyl sulfone & 24 & 1.5 & none & \\
methanesulfonic acidd & 24 & 2.0 & none & \\
\hline
\end{tabular}

"See the corresponding footnote in Table $2 .{ }^{b}$ Analyzed by GC. "Along with 1 equiv of hydrogen evolution. "Immediately 1 equiv of hydrogen evolved.

Table 9. Reaction of Lithium Thexyl'butoxyborohydride with Representative Epoxides at $0^{\circ} \mathrm{C}^{17}$

\begin{tabular}{|c|c|c|c|c|}
\hline Compound & $\begin{array}{c}\text { Time } \\
\text { (h) }\end{array}$ & $\begin{array}{l}\text { Ratio of } \\
\text { Igt/cmpd }\end{array}$ & Product & $\begin{array}{l}\text { Yield } \\
(\%)^{h}\end{array}$ \\
\hline \multirow[t]{4}{*}{ 1.2-epoxyoctane } & 0.5 & 0.5 & 1-octanol & 1 \\
\hline & & & 2-octanol & 98 \\
\hline & 0.5 & 1 & 1-octanol & 0.5 \\
\hline & & & 2-octanol & 99.4 \\
\hline \multirow[t]{4}{*}{ styrene oxide } & 0.5 & 0.5 & 1-phenylethanol & 96 \\
\hline & & & 2-phenylethanol & 4 \\
\hline & 0.5 & 1 & 1-phenylethanol & 98.5 \\
\hline & & & 2-phenylethanol & 0.5 \\
\hline cyclohexene oxide & 0.5 & 0. & syclohexanol & 99.9 \\
\hline
\end{tabular}

"See the conesponding footnote in Table $2 .{ }^{b}$ Analyzed by GC

summarized in Table 9. The aliphatic epoxides examined were rapidly reduced with a quantitative amount of the reagent to give the $\mathrm{S}_{\mathbf{2} 2}$-type of ring-opened products exclusively, whereas the reaction of styrene oxide, an aromatic one, with a theoretical amount of the reagent afforded a mixture of $96 \% 1$-phenylethanol and 4\% 2-phenylethanol. However, the reagent in an excess amount $\left(\mathrm{H}^{-} / \mathrm{compd}=2\right)$ reduced styrene oxide to give an almost single product, 1-phenylethanol, in a yield of $98.5 \%$.

\section{Conclusion}

The reducing power of a newly synthesized monoalkylmonoalkoxyborohydride, lithium (2,3-dimethyl-2-butyl)-tbutoxyborohydride (lithium thexyl'butoxyborohydride, Li $\mathrm{Thx}^{t} \mathrm{BuO} \mathrm{BH}_{2}, 1$ ), in a mixed solvent of THF and pentane toward organic compounds containing representative functional groups under practical conditions has been investigated. The results reveal that the reducing power of the reagent is somewhere between the dialkylborohydride and the parent borohydride. The reducing power of the lithium borohydride derivatives appears in the order of $\mathrm{LiR}_{3} \mathrm{BH}>\mathrm{LiR}_{2} \mathrm{BH}_{2}>$ $\mathrm{LIR}(\mathrm{RO}) \mathrm{BH}_{2}>\mathrm{LiBH}_{4}>\mathrm{Li}(\mathrm{RO})_{3} \mathrm{BH}$. The introduction of alkyl and alkoxy groups into the parent borohydride affords an interesting and unique reducing characteristics. Consequently, this reagent should find a valuable role as a reagent of choice in organic synthesis.

\section{Experimental Section}

All glassware used in the experiments was predried thoroughly in a drying oven and cooled under a dry nitrogen atmosphere. Hypodemic syringes were used to transfer solutions. All reactions were carried out under a static pressure of nitrogen in flasks fitted with septum-covered sidearms with use of standard techniques for handling airsensitive materials, ${ }^{1+}$

Materials. Most of the organic compounds utilized in this study were commercial products of the highest purity. They were further purified by distillation or recrystallization when necessary. Tetralyydrofuran (THF) was distilled from sodium benzophenone ketyl and stored under dry nitrogen. A solution of tert-butyllithium was purchased from the Aldrich Chemical Co. A solution of $\mathrm{BH}_{3}$ in THF was synthesized by the reaction of sodium borohydride and dimethyl sulfate. ${ }^{l}$

Instruments. GC analyses were carried out on a Varian 3300 FID with capillary columns of DB-WAX $(30 \mathrm{~m})$ and HP-FFAP (25 m). All GC yields were determined with use of a suitable internal standard and authentic mixtures. NMR spectrometer used was a Bruker AMX 300.

Preparation of a Solution of Thx ${ }^{t} \mathbf{B u O B H}$. An ovendried, 1-L, round-bottom flask with a sidearm, equipped with a magnetic stirring bar and an adapter, was attached to a mercury bubbler. The flask was flushed with dry nitrogen and then maintained under a static pressure of nitrogen. The flask was charged with $329 \mathrm{~mL}$ of a $1.52 \mathrm{M}$ solution of $\mathrm{BH}_{3}$ THF (500 mmol) and maintained at $0^{\circ}$ with the aid of icewater bath. Into the flask $44.2 \mathrm{~g}$ of 2,3-dimethyl-2-butene (525 mmol) was injected slowly and the mixture was stirred for $3 \mathrm{~h}$. The concentration of a solution of thexylborane was estimated gasometrically to indicate $1.25 \mathrm{M}$. The ${ }^{11} \mathrm{~B}$ NMR spectrum showed a triplet $\left(J_{\mathrm{B} \cdot \mathrm{H}}=359 \mathrm{~Hz}\right)$ centered at $\delta 24.4$ ppm relative to $\mathrm{BF}_{3} \cdot \mathrm{OEt}_{2}$.

Into the flask was charged with $320 \mathrm{~mL}$ of a solution of thexylborane ( $400 \mathrm{mmol}$ ) thus prepared above and the flask was inmersed into an ice-water bath. To this $31.4 \mathrm{~g}$ of tertbutyl alcohol ( $420 \mathrm{mmol}$ ) was injected dropwise. After the complete evolution of lydrogen, the reaction mixture was stirred for additional $1 \mathrm{l}$. The concentration of the solution was estimated by hydrolysis to indicate $1.07 \mathrm{M}$. The ${ }^{11} \mathrm{~B}$ NMR spectrum exhibited a doublet $\left(J_{\mathrm{B} \cdot \mathrm{H}}=390 \mathrm{~Hz}\right)$ centered at $\delta 48.3$ ppm.

Preparation of a Solution of $\mathrm{Li} \mathrm{Thx} \mathrm{TuOBH}_{2}, 1$. Into a 100 -mL flask was placed $40 \mathrm{~mL}$ of a solution of Thx$\mathrm{BuOBH}$ (40.3 mmol) thus prepared above and the flask was cooled to $-30^{\circ}$ by use of a refrigerating bath circulator. To this flask was added $26 \mathrm{~mL}$ of a precooled $1.7 \mathrm{M}$ solution of tert-butyllithium (44 mmol) in pentane dropwise with vigorous stirring. After the reaction mixture was stirred for additional $1 \mathrm{~h}$ at $-30^{\circ}$, the flask was brought to $0^{\circ}$. The concentration of the reagent was estimated gasometrically by hydrolyzing an aliquot to give $0.60 \mathrm{M}$ of $\mathrm{Li} \mathrm{ThxtBuOBH}_{2}:{ }^{11} \mathrm{~B}$ NMR (THF and pentane) $\delta 7.6 \mathrm{ppm}\left(t, J_{\mathrm{B} \cdot \mathrm{H}}=219 \mathrm{~Hz}\right){ }^{10}$

General Procedure Used for Reductions. The following 
procedure was used for general reductions. The reduction of benzaldehyde is described as an example of the experimental procedure. The reagent 1 solution, $16.7 \mathrm{~mL}$ of 0.60 M (10 mmol of the reagent, $20.0 \mathrm{mmol}$ of hydride), was introduced into a dried, 50 -mL flask fitted with a rubber syringe cap on an inlet port, a magnetic stirring bar, and a bent adapter connected to a gas burette through a reflux condenser and a dry ice vapor trap. The flask was immersed in an ice-water bath, the stirred solution was maintained at $0^{\circ}$, and $1.07 \mathrm{~g}$ of benzaldehyde ( $10.0 \mathrm{mmol}$ ) in $2 \mathrm{~mL}$ of THF and tridecane ( $5 \mathrm{mmol}$ ) as an internal standard was injected. After $30 \mathrm{~min}$, a $4.0-\mathrm{mL}$ aliquot of the reaction mixture was

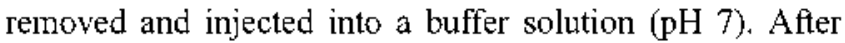
then, the solution was treated with $2 \mathrm{~mL}$ of $3 \mathrm{~N} \mathrm{NaOH}$ and 2 $\mathrm{mL}$ of $30 \% \mathrm{H}_{2} \mathrm{O}_{2}$ with stirring at room temperature for $2 \mathrm{~h}$. The aqueous layer was saturated with $\mathrm{K}_{2} \mathrm{CO}_{3}$. The separated organic layer was washed with saturated $\mathrm{NaCl}$ solution and dried over anhydrous $\mathrm{MgSO}_{4}$. The gas chromatographic analysis showed $99.5 \%$ benzyl alcohol. Aliquot was also removed after $1.0 \mathrm{~h}$ of the reaction time and worked up for GC analysis. The yield appeared to be $99 \%$. Obviously, the reaction was complete within $0.5 \mathrm{~h}$.

General Procedure for Stereoselectivity Studies. The reduction of 2-methylcyclohexanone is described as representative. To a $50-\mathrm{mL}$ flask was added $8.4 \mathrm{~mL}$ of $0.60 \mathrm{M}$ solution of the reagent $1(5.0 \mathrm{mmol})$. The flask was cooled to $-20^{\circ}$ with use of a refrigerating bath circulator and to this was added $1.0 \mathrm{~mL}$ of a precooled solution of 2-methylcyclohexanone $(0.29 \mathrm{~g}, 2.5 \mathrm{mmol})$ in THF. After $30 \mathrm{~min}$, the reaction mixture was quenched with $3 \mathrm{~N} \mathrm{NaOH}$ and oxidized with $30 \% \mathrm{H}_{2} \mathrm{O}_{2}$ for $2 \mathrm{~h}$ at room temperature. The aqueous layer was saturated with $\mathrm{K}_{2} \mathrm{CO}_{3}$. The separated organic layer was washed with saturated $\mathrm{NaCl}$ and dried over anhydrous $\mathrm{MgSO}_{+}$. The gas chromatographic analysis with use of a 30 m capillary column of DB-WAX showed no presence of the starting ketone (i.e., $100 \%$ conversion) and $>99.5 \%$ cis- 2 methylcyclohexanol along with only trace amount of the trans-isomer. The results are summarized in Table 4.

Acknowledgment. This study was supported by the Korea Science and Engineering Foundation Grant (R012001-00057).

\section{References and Notes}

1. Yoon, N. M.; Cha. J. S. J. Korean Chem. Soc. 1977. 21, 108.

2. Krishnamurthy, S. AIdrichmica Acta 1974, 7. 55 .

3. Krishnamurthy. S.; Brown. H. C. J. An. Chem. Soc 1976. 98, 3383.

4. Krishnemuthy, S.; Brown, H. C. J. Org. Chem. 1976, 41, 3064.

5. Brown, H. C.: Kim, S. C. Symthesis 1977, 635.

6. Brown, H. C.; Mathew, C. P.; Pyun. C.; Son, J. C.; Yoon, N. M. J. Org. Chem. 1984. 49.3091.

7. Cha. J. S.; Kim. J. E.; Lee, J. C.; Yoon, M. S. Bull. Korean Chem. Soc. 1986, 7, 66.

8. (a) Brown, H. C.; Moerikoter, A. W. J. Am. Chem Soc. 1962, 84 , 1478. (b) Brown, H. C.; Klender, G. J. Inorg. Chem 1962, 1, 204. (c) Brown. H. C.; Heim, P.; Yoon. N. M. J. Org. Chem. 1972, 37, 2942.

9. (a) Corey, E. J.; Becker, K. B.; Varma, R. K. J. Am. Chem. Soc. 1972, 94, 8616. (b) Corey, E. J.: Albonico, S. M.: Koelliker, U.: Schaaf, T. K.; Varma, R. K. ibid. 1971, 93, 1491. (c) Corey, E. J.; Varma, R. K. ibid. 1971, 93,7319 . (d) Brown, H. C.: Kramer, G. W.; Hubbard, J. L.; Krishnamurthy. S. J. Organomet. Chem. 1980. 188,1 .

10. The ${ }^{11} \mathrm{~B}$ NMR spectrum of $\mathrm{Li}$ Thx ${ }^{\prime} \mathrm{BuOBH} \mathrm{H}_{2}$ at ambient temperature exhibited a clean triplet at $\delta 7.6 \mathrm{ppm}$ along with minor unknown peaks in the range of $\delta 45-55 \mathrm{ppm}$.

11. Brown, H. C.: Cha, J. S.; Nazer, B. J. Org. Chem. 1984, 49, 2073.

12. Cha, J. S.; Yoon, M. S.; Lee, K. W.; Lee, J. C. Heterocycles 1988, 27, 1455 ,

13. Brown. H. C.; Krishnamurthy. S. J. An. Chem. Soc 1972. 94 , 7159 .

14. Brown, H. C.; Kramer, G. W.; Levy, A. B.: Midland, M. M. Organic Symthesis via Boranes: Wiley-Interscience: New York, 1975 . 